\title{
Tinctorial behavior of curaua and banana fibers and dyeing wastewater treatment by porous alumina membranes
}

\author{
Fernando R. Oliveira ${ }^{a}$, Felipe M.F. Galvão ${ }^{a}$, Tábhita L.T. da Silva ${ }^{a}$, \\ Késia Karina O.S. Silva ${ }^{a}$, José H.O. Nascimento ${ }^{\mathrm{a}}$, António P. Souto ${ }^{\mathrm{b}}$, Andrea Zille ${ }^{\mathrm{b}, *}$ \\ ${ }^{a}$ Departamento de Engenharia Têxtil, Federal University of Rio Grande do Norte, Campus Universitário-CT-DET Av. Salgado \\ Filho, 3000_Lagoa Nova, Natal, RN 59078-970, Brazil, Tel. +5584 9814 4994; email: fernandomoc@hotmail.com (F.R. Oliveira), \\ Tel.+55849198 7207; email: felipefmfg@gmail.com (F.M.F. Galvão),Tel.+55849649 0991; email: tlt_leia@yahoo.com.br (T.L.T.da Silva), \\ Tel. +55849818 2142; email: kesiasouto@hotmail.com (K.K.O.S. Silva), Tel. +55849158 3301; email: heribertoo@ufrnet.br \\ (J.H.O. Nascimento) \\ ${ }^{b} 2$ C2T_Centro de Ciência e Tecnologia Têxtil, Departamento de Engenharia Têxtil, Universidade do Minho, 4800-058 Guimarães, \\ Portugal, Tel. +351 253 510280; email: souto@det.uminho.pt (A.P. Souto), Tel. +351 253510285; email: azille@2c2t.uminho.pt
} (A. Zille)

Received 15 October 2014; Accepted 12 June 2015

\begin{abstract}
Physicochemical and dyeing properties using reactive dyes of curaua and banana fibers were studied by means of color strength $(K / S)$, differential scanning calorimetry (DSC), scanning electron microscopy (SEM), and Fourier transform infrared (FTIR) spectroscopy analyses. SEM analysis of alkali-treated fibers showed an increase in roughness due to surface lignin and hemicellulose defibrillation. DSC analysis showed for all the samples an endothermic and an exothermic peak at 70-80 and $340-360^{\circ} \mathrm{C}$ due to the loss of adsorbed/ absorbed water and to decomposition of $\alpha$-cellulose, respectively. Alkali-treated fibers displayed a second peak around $290^{\circ} \mathrm{C}$ attributed to the degradation of hemicellulose. FTIR spectra of the studied fibers show similar bands with different intensities attributed to the main components of cellulose-based materials. Alkali-pretreated fibers demonstrated excellent dyeing ability for all the tested dyes. Dye absorption depends on the chemical fiber, dye structure, and concentration. The results of washing fastness are very good for all the tested fibers. The dyeing effluent treated with an advanced microfiltration method using an improved alumina ceramic membrane shows an average efficiency of $98 \%$ in turbidity and color reduction. Low-cost ceramic alumina microfiltration membranes are a very promising advanced treatment for textile industrial effluents allowing water reuse.
\end{abstract}

Keywords: Dyeing; Banana; Curaua; Ceramic; Alumina; Porous membranes; Textile effluent; Filtration

\footnotetext{
*Corresponding author.

Presented at the International Congress on Water, Waste and Energy Management 16-18 July 2014, Porto, Portugal
}

1944-3994/1944-3986 @ 2015 Balaban Desalination Publications. All rights reserved. 


\section{Introduction}

Lignocellulose is the major structural component of woody plants and non-woody plants such as grass and represents a major source of renewable organic matter [1]. The lignocellulosic natural tropical fibers from agricultural waste have recently received considerable attention in the literature as an alternative to well-known and common fibers such as cotton, jute, hemp, flax, sisal, and coir [2,3]. Brazil, which produces many lignocellulosic materials, is in a unique climatic and geographic position amongst South American countries, having an area of approximately 8.5 million $\mathrm{km}^{2}$ of which about $5-6 \%$ are arable lands, $22 \%$ permanent pastures, and 58\% forest and woodland [4]. Far away from lagging behind other countries, Brazil is in the forefront of utilization of its resources, as research projects in this area have received persistent funding from various organizations to the study and exploitation of its rich renewable natural materials, including fibers such as banana, curaua, pineapple, etc. These fibers present vast diversity of applications because of their unique properties such as lower density, less wear of processing equipment, higher flexibility, and high specific strength, and has the possibility of mass production at affordable cost, while contributing to the biodegradation and renewal of the ecological cycle [5]. Lignocellulosic natural fibers have already established a track record in several different areas of engineering such as, civil, automotive, and architecture among others [6]. Curaua and banana are among the tropical fibers, the two with greater potential to be used as an engineering material owing to its reported high mechanical resistance associated with low density values [7]. Curaua fibers are leaf fibers extracted from an Amazon forest plant (Ananas erectifolius) closely related to the pineapple. There are four varieties of plants: white, purple, red, and bright white. The most common are the purple ones, with purple-reddish leaves, and the white curaua, with light green leaves [8]. Curaua fibers have low cost of production and offer a relatively high tensile strength level and which is necessary for practical applications [9]. Furthermore, in the past five years, curaua fibers have gradually gained importance in Brazilian economy as a suitable reinforcing material for environmentally friendly composites [10,11]. However, very few information is available about tinctorial behavior and physicochemical properties of the curaua fibers compared to other vegetal fibers.

Banana fibers are extracted from the dried stalk of banana trees, a several kinds of large herbaceous flowering plants in the genus Musa. Obtained from the waste product of banana cultivation, banana fiber possesses lower density and good specific strength properties comparable to those of conventional materials, like glass fibers [12,13]. Moreover, banana fibers show good wet absorption allowing easy dyeing with brighter shade than jute and blending with cellulose fibers as cotton. However, banana fibers are associated with some challenges including high moisture uptake, low thermal stability, and low bonding with polymers [14].

Previous studies have shown that alkali treatments are effective in removing impurities from this type of fibers, decreasing moisture sorption, and enabling mechanical bonding, and thereby improving matrixreinforcement interaction and dyeing ability [15]. Despite these naturals fibers are well established, for example, as reinforcement in composite materials, the dyeing properties of curaua and banana fibers are not well studied yet. Thus, the physicochemical and dyeing properties of these materials were studied by means of color strength, differential scanning calorimetry (DSC), scanning electron microscopy (SEM), and Fourier transform infrared (FTIR) spectroscopy analyses using reactive conventional dyes. Moreover, the obtained dyeing effluent was treated with an advanced microfiltration method using an improved alumina ceramic membrane synthesized in our laboratory. Finally, the obtained filtrate was analyzed for color and turbidity reduction.

\section{Materials and methods}

\subsection{Materials}

Banana and curaua fibers were supplied by Embrapa Amazonia Ocidental, Brazil. The three different reactive dyes C.I. Reactive Brilliant Yellow 160 (Y160), C.I. Reactive Blue 220 (B220), and C.I. Reactive Red 198 (R198) were supplied by Dystar Textil farben, Frankfurt, Germany. The selected dyes are a light-, a dark-, and a medium-shade vinyl sulfones reactive dye that can be efficiently used on linen, hemp, and other cellulose (plant) fibers as well as in silk and wool [16]. A reactive $\alpha$-alumina $\left(\mathrm{Al}_{2} \mathrm{O}_{3}\right)$ (Alcoa-CT 3000 SG, USA, $\left.d_{50}=0.5 \mu \mathrm{m}\right)$ was screened in a 200-mesh sieve before processing. All the other reagents were analytical grade purchased from SigmaAldrich, St. Louis, MO, USA and used without further purification.

\subsection{Scouring}

Banana and curaua fibers were scoured, as reported by Dystar instruction manual [17], with a 
solution of $3 \mathrm{~mL} \mathrm{~L}^{-1} \mathrm{NaOH}\left(38^{\circ} \mathrm{Be}\right), 2 \mathrm{~mL} \mathrm{~L}^{-1} \mathrm{H}_{2} \mathrm{O}_{2}$ (50\%), $0.5 \mathrm{~mL} \mathrm{~L}^{-1}$ peroxide stabilizer, and $0.5 \mathrm{~mL} \mathrm{~L}^{-1}$ Lutensol AT $25^{\circledR}$ at $70^{\circ} \mathrm{C}$ for $1 \mathrm{~h}$ in an Ahiba Spectradye-Datacolor dyeing apparatus (Lawrenceville, NJ, USA) at a liquor to fabric ratio of 30:1. The program was started at $30^{\circ} \mathrm{C}$ and raised at a rate of $2^{\circ} \mathrm{C} \mathrm{min}{ }^{-1}$ up to $98^{\circ} \mathrm{C}$, and kept at this temperature for $30 \mathrm{~min}$. Afterwards, the fibers were neutralized with $1 \mathrm{gL}^{-1}$ acetic acid at $80^{\circ} \mathrm{C}$ for $10 \mathrm{~min}$ and washed with tap water. They were then dried at $60^{\circ} \mathrm{C}$ for either $24 \mathrm{~h}$ or until a constant weight was obtained [18].

\subsection{Dyeing}

The three different reactive dyes (C.I. Reactive Brilliant Yellow 160, C.I. Reactive Blue 220, and C.I. Reactive Red 198) at the concentration of 1,2, and 3\% o.w.f were prepared in a $100 \mathrm{~mL}$ distilled water solution containing $\mathrm{NaCl}\left(14,20\right.$, or $\left.25 \mathrm{~g} \mathrm{~L}^{-1}\right), \mathrm{Na}_{2} \mathrm{CO}_{3}$ (6.3, 8.1 , or $\left.9 \mathrm{~g} \mathrm{~L}^{-1}\right)$, and dye $(3,6$, or $15 \mathrm{~mL})$. The dyeing method was carried out, as reported by Dystar instruction manual [17], with $3 \mathrm{~g}$ of fibers in a laboratorial "Ibelus" machine equipped with infrared heating with a liquor ratio of 1:30 and $\mathrm{pH}$ around 10-12 using stainless steel dye-pots with $200 \mathrm{~cm}^{3}$ of capacity each. The program was started at $20^{\circ} \mathrm{C}$ and raised at a rate of $2^{\circ} \mathrm{C} \mathrm{min}{ }^{-1}$ up to $30^{\circ} \mathrm{C}$, and kept at this temperature for $15 \mathrm{~min}$. Then, the temperature was raised at a rate of $2^{\circ} \mathrm{C} \mathrm{min}^{-1}$ up to $60^{\circ} \mathrm{C}$ and kept at this temperature for $40 \mathrm{~min}$. After dyeing, samples were washed with a $1 \mathrm{~g} \mathrm{~L}^{-1}$ of non-ionic detergent solution at $30^{\circ} \mathrm{C}$ during $30 \mathrm{~min}$ and then rinsed with water for another $15 \mathrm{~min}$ in order to remove unbounded dye. The absorption measurements for the calculation of dyebath exhaustion process with reactive dye were obtained in a Unicam UV-vis UV2 spectrophotometer. The washing fastness was evaluated in accordance to the stipulated in standard ISO 105 C06, method A1S, at temperature of $40^{\circ} \mathrm{C}$ [18].

\subsection{Fourier transform infrared (FTIR)}

The attenuated total reflectance ATR-FTIR spectra of the banana and curaua samples before and after scouring process were recorded in a Nicolet Avatar 360 FTIR spectrophotometer (Madison, USA). The spectra were collected in the region of $4,000-400 \mathrm{~cm}^{-1}$ and at a resolution of $16 \mathrm{~cm}^{-1}$.

\subsection{Differential scanning calorimetry (DSC)}

The DSC analysis was carried on a Mettler Toledo DSC822 (Columbus, OH, USA), based on the standards ISO 11357-1:1997, ISO 11357-2:1999 and ISO 11357-3:1999. The samples were previously dried at $60^{\circ} \mathrm{C}$ for $1 \mathrm{~h}$ and placed into an aluminum sample pan. The analysis was carried out in nitrogen atmosphere with a flow rate of $20 \mathrm{~mL} \mathrm{~min}^{-1}$ and heating rate of $10^{\circ} \mathrm{C} \mathrm{min}$. The thermogram was obtained in the range of $0-450^{\circ} \mathrm{C}$. The graph was plotted with heat flow vs. temperatures.

\subsection{Scanning electron microscopy (SEM)}

Morphological analyses of membranes before and after filtration as well as banana and curaua samples were carried out with an ultra-high resolution Field Emission Gun Scanning Electron Microscopy (FEG-SEM), NOVA 200 Nano SEM, FEI Company. Secondary electron images were performed with an acceleration voltage between 5 and $10 \mathrm{kV}$. Backscattering electron images were made with an acceleration voltage of $15 \mathrm{kV}$. Samples were covered with a film of $\mathrm{Au}-\mathrm{Pd}(80-20 \mathrm{wt} \%)$ in a high-resolution sputter coater, 208HR Cressington Company, coupled to with a MTM-20 Cressington High Resolution Thickness Controller.

\subsection{Color strength $(K / S)$}

Color intensity of the dyed fibers was measured using a Konica Minolta CM-2600 spectrophotometer with D65 illuminant, over the range of $390-700 \mathrm{~nm}$. The average of three reflectance measurements, taken at different positions on the dyed fabric, was adopted. The relative color strength $(K / S$ values) was then established at standard illuminant D65 (LAV/Spec. Excl., d/8, D65 $/ 10^{\circ}$ ), according to the Kubelka-Munk equation, where $K$ and $S$ stand for the light absorption and scattering, respectively. The shift of the coordinates of the color in the cylindrical color space, based on the theory that color is perceived by black-white $\left(L^{*}\right.$, lightness), red-green $\left(a^{*}\right)$, and yellow-blue $\left(b^{*}\right)$ sensations, was summarized by the overall color difference $\left(\Delta E^{*}\right)$ value. The value of $\Delta E^{*}$ represents the overall color difference between the sample and the standard.

\subsection{Effluent characterization}

Turbidity (TU) was measured by a Digimed turbidimeter HDM-TU type. Effluent color change was determined using a UV-vis spectrophotometer (HACH, DR2000) before and after microfiltration treatment at the maximum absorption wavelengths of each dye. 


\subsection{Microfiltration experiments}

Ceramic microfiltration membranes were prepared by sintering of alumina powders mixed with binders as previously reported [19]. The alumina paste was produced in an aqueous solution of polyvinyl alcohol (PVA) and ethylene glycol (EG) as binders in the proportion 70:30 (Vetec Química Fina LTDA, Brazil). PVA was dissolved at $65^{\circ} \mathrm{C}$ for $30 \mathrm{~min}$. Then, EG was slowly added to PVA solution under continuous stirring for $60 \mathrm{~min}$. Finally, alumina was mixed in the proportion 3:1 (Granulometry $D_{50} \quad 1.8 \mu \mathrm{m}$ and $D_{\mathrm{M}}$ $2.3 \mu \mathrm{m})$. A small amount of sodium silicate $\left(\mathrm{Na}_{2} \mathrm{SiO}_{3}\right)$ (Pernambuco Química, Brazil) was added to the suspensions to avoid flocculation and to adjust density. The obtained ceramic paste was dried for $24 \mathrm{~h}$ at $105^{\circ} \mathrm{C}$ and mixed in stainless steel ball mill for 30 min. The resulting powder was sieved in a 48-mesh standard screen. A fixed amount of pre-wetted screened powder ( $7 \mathrm{~g}$ including $10 \%$ of water) was uniaxially pressed at a pressure of $37.5 \mathrm{MPa}$ for $20 \mathrm{~s}$ with the help of stainless steel mold, designed for single-ended pressing, to form a circular disk-shaped support having $5 \mathrm{~cm}$ diameter. Supports were first dried at ambient condition for $24 \mathrm{~h}$ and then dried in hot air oven at 100 and $200^{\circ} \mathrm{C}$ for $24 \mathrm{~h}$. This drying process ensures maximum moisture removal without thermal stresses. The dried samples were placed vertically in the grooves of insulation bricks to ensure uniform sintering. Then, the supports were sintered in a muffle furnace at air atmosphere at $1,475^{\circ} \mathrm{C}$ for $2 \mathrm{~h}$ with a heating rate of $3{ }^{\circ} \mathrm{C} \mathrm{min}{ }^{-1}$ from 32 to $500^{\circ} \mathrm{C}$, and $5^{\circ} \mathrm{C} \mathrm{min}{ }^{-1}$ from 500 to $1,475^{\circ} \mathrm{C}$, and a cooling rate of $10^{\circ} \mathrm{C} \mathrm{min}{ }^{-1}$ from 1,475 to $32^{\circ} \mathrm{C}$. The rate of heating in the furnace was kept low to minimize bending. The cooling rate was kept low to reduce cooling stress and to achieve homogeneity of the microstructure. It also improves the porosity of the support due to the formation of large grain. Effluents were microfiltered with a vacuum pump (Tecnal, TE-058) working at $600 \mathrm{~mm} \mathrm{Hg}(78.92 \mathrm{kPa})$ in a Sterfil ${ }^{\circledR}$ polysulfone filtration system (Millipore). The filtration cell allows testing membranes with a $5 \mathrm{~cm}$ diameter and a working volume of $250 \mathrm{~mL}$. The solution in the chamber was stirred by a Teflon-coated magnetic bar at $300 \mathrm{rpm}$. All experiments were carried at $25^{\circ} \mathrm{C}$. Each experiment was performed in triplicate. The t-Student test was used to test the statistical significance of the attained results at when $p<0.001$.

\section{Results and discussion}

Fig. 1 shows the SEM analysis of untreated and alkali-treated banana fibers. A very similar result was obtained for curaua (data not shown). The raw fibers display a clean and smooth surface while, after alkali treatment, an increase in roughness due to defibrillation was observed. Alkali treatment leads to the increase in the amount of amorphous cellulose reducing the crystalline phase due to the removal of hydrogen bonding from the network structure. The alkali-modified fibers appear not well separated and bundled with a decreased diameter as previously observed [20]. $\mathrm{NaOH}$ different from other alkalis can cause a complete lattice transformation from cellulose I to cellulose II and also affect non-cellulosic components such as hemicellulose, lignin, and pectin. In the SEM image, it can be noted that the cementing materials of the outer surface such as lignin and hemicellulose present in the fibers was completely dissolved after alkali treatment exposing the inner fibrillar surface [21].

The heating DSC curves for raw and alkali-treated banana and curaua fibers were expressed in terms of heat flow and presented in Fig. 2. All the analyzed samples display an endothermic peak between 50 and $100^{\circ} \mathrm{C}$ due to the loss of adsorbed/absorbed water. The higher temperature for this peak observed for the alkali-treated banana fibers suggest that these fibers have a higher percentage of coordinated water in its structure. Untreated banana fibers show a welldefined exothermic peak at $360^{\circ} \mathrm{C}$ attributed to decomposition of $\alpha$-cellulose. On the other hand, in the alkali-treated banana fibers, cellulose degradation temperatures peak is found to decrease from 360 to $340^{\circ} \mathrm{C}$ due to the oxidation of the lignin or hemicelluloses and by the formation of new intermonomeric bonds [7]. This is also confirmed by the presence of a second peak around $290^{\circ} \mathrm{C}$ attributed to the degradation of hemicellulose. The curaua fibers display a similar behavior, however the small exothermic peak attributed to the hemicellulose degradation can also be observed in the untreated control fibers. Moreover, despite the alkali-treated curaua fibers show the peak of the hemicellulose at the same temperature of banana fiber, no decrease in cellulose degradation temperature can be observed. This behavior could be related to the full decomposition of cellulose in the curaua that might be attributed to quick volatilization reactions, leading to small amount of solid residue [22].

The structural characterization of fibers before and after alkali treatment was performed by ATR-FTIR as reported in Fig. 3. The FTIR spectra of the studied fibers can be mainly attributed to the main components of cellulose-based materials [23]. All samples contained similar bands, but differences in their intensities. The broad band at $3,300 \mathrm{~cm}^{-1}$ represents 

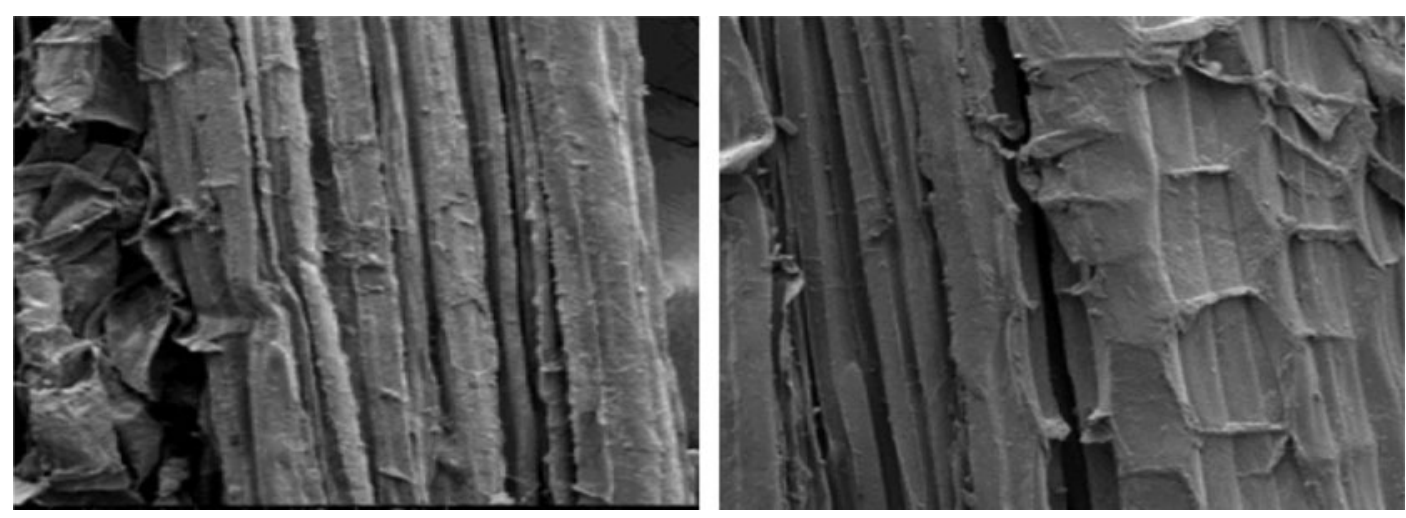

Fig. 1. SEM images $(2,000 \times)$ of the surface of banana fibers before and after bleaching.

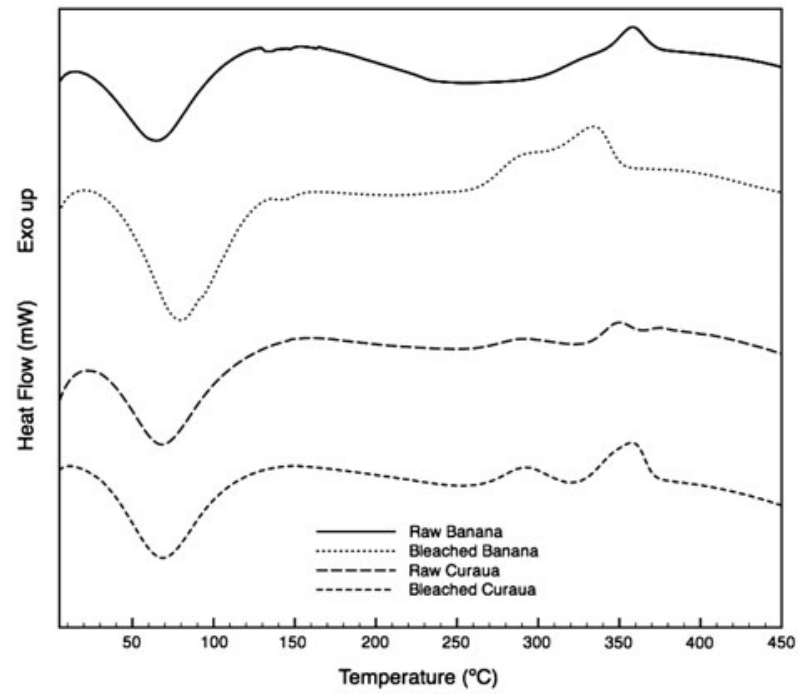

Fig. 2. DSC analyses of banana and curaua fibers before and after bleaching from 5 to $450^{\circ} \mathrm{C}$, performed at a heating rate of $10^{\circ} \mathrm{C} \mathrm{min}^{-1}$.

the typical $\mathrm{O}-\mathrm{H}$ stretching. The $\mathrm{OH}$ compounds may include absorbed water, aliphatic primary and secondary alcohols found in cellulose, hemicellulose, lignin, and carboxylic acids in extractives. The absorption band near the $\mathrm{OH}$ stretching vibrations at 2,900 and $2,850 \mathrm{~cm}^{-1}$ are associated to aliphatic and aromatic $\mathrm{CH}$ stretching vibrations of carbohydrates and lignin [24]. Others typical bands of cellulose structural units, which are similar to those reported earlier for other lignocellulosic fibers such as sisal, can be observed at $1,730 \mathrm{~cm}^{-1}(\mathrm{C}=\mathrm{O}$ acidic stretching vibration) and $1,644 \mathrm{~cm}^{-1}(\mathrm{C}=\mathrm{O}$ aldehyde stretching vibration and also adsorbed/absorbed water molecules) [25]. The large region of absorption involving overlapping bands in the range of $1,700-1,100 \mathrm{~cm}^{-1}$ is attributed to the $\mathrm{C}-\mathrm{C}, \mathrm{C}=\mathrm{C}, \mathrm{OH}, \mathrm{CO}, \mathrm{CH} n, \mathrm{C}-\mathrm{O}-\mathrm{C}$,

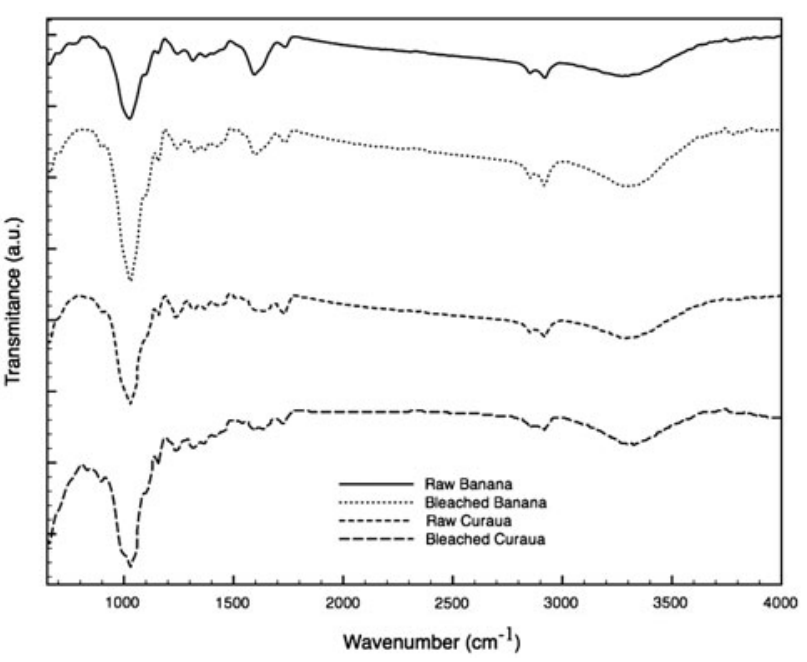

Fig. 3. ATR-FTIR spectra of banana and curaua fibers before and after bleaching.

$\mathrm{CH}$ aromatic linkages bands [14]. The absorbance peak at $1,020 \mathrm{~cm}^{-1}$ indicative of $\mathrm{C}-\mathrm{O}$ stretching present in alcohol of hemicellulose is more pronounced in the alkali-treated fibers due to the loss of lignin from the fibers that expose the hemicellulose of the inner structure of the fiber [26]. On the other hand, the reduction in the alkali-treated fibers of the bands around $1,320 \mathrm{~cm}^{-1}$ may be attributed to the oxidation of the lignin belonging to the syringic group. The other absorbance peaks did not show any significant change in intensity.

According to the results in Table 1, the coloristic strength, expressed as $K / S$, is directly proportional to the concentration of the colorant in the substrate and indicates the dye adsorption and fixation. In dyeing experiments, $K / S$ reflected the amount of fixed dye, since all the unfixed dyestuff was presumably washed off. For the same dye, $K / S$ and lightness values varied 
Table 1

Color strength $(K / S)$ and shift of the coordinates of the color in the cylindrical color space as lightness $(L)$, red-green $(a)$ and yellow-blue $(b)$ of the curaua and banana fibers and commercial cotton dyed at different dye concentrations

\begin{tabular}{|c|c|c|c|c|c|c|c|c|c|c|c|c|}
\hline \multirow[b]{2}{*}{ Dye (\% o.w.f) } & \multicolumn{4}{|c|}{ Cotton fibers } & \multicolumn{4}{|c|}{ Banana fibers } & \multicolumn{4}{|c|}{ Curaua fibers } \\
\hline & $K / S$ & $L$ & $a$ & $b$ & $K / S$ & $L$ & $a$ & $b$ & $K / S$ & $L$ & $a$ & $b$ \\
\hline$Y 1601$ & 87.3 & 86.8 & -4.61 & 83.7 & 78.9 & 67.4 & 13.8 & 44.8 & 87.6 & 66.4 & 20.2 & 55.2 \\
\hline$Y 1602$ & 132.2 & 84.9 & -4.03 & 88.6 & 141.4 & 58.4 & 20.8 & 48.7 & 201.4 & 60.6 & 33.2 & 64.9 \\
\hline Y160 3 & 170.1 & 82.2 & -2.47 & 91.8 & 183.3 & 57.3 & 27.9 & 53.7 & 216.3 & 58.7 & 37.4 & 63.1 \\
\hline$R 1981$ & 104.85 & 42.68 & 44.45 & 1.76 & 119.7 & 45.5 & 33.9 & 6.4 & 94.4 & 46.0 & 46.2 & -0.3 \\
\hline R198 2 & 165.99 & 39.46 & 47.28 & 3.32 & 172.5 & 40.2 & 41.8 & 5.3 & 136.4 & 42.7 & 50.5 & 2.6 \\
\hline R198 3 & 251.68 & 34.42 & 46.03 & 7.08 & 241.2 & 36.4 & 47.0 & 6.0 & 213.2 & 36.0 & 45.9 & 5.8 \\
\hline B220 1 & 175.0 & 31.9 & -5.9 & -18.0 & 122.1 & 44.7 & -10.3 & -2.7 & 105.2 & 42.9 & -7.6 & -17.1 \\
\hline$B 2202$ & 289.3 & 25.4 & -4.5 & -16.8 & 123.8 & 42.0 & -9.2 & -9.2 & 210.9 & 31.9 & -4.2 & -17.9 \\
\hline B220 3 & 388.9 & 21.5 & -3.4 & -15.0 & 258.1 & 29.6 & -5.4 & -13.1 & 325.3 & 25.4 & -1.4 & -16.4 \\
\hline
\end{tabular}

considerably in function of the used substrate. The highest $K / S$ values were obtained for cotton and alkali-treated curaua fibers dyed with blue dye at the concentration of $3 \%$ indicating higher dye absorption. However, the dye absorption in cotton, banana, and curaua fibers also depends on the chemical dye structure and concentration. Yellow dye shows higher adsorption in curaua fibers while banana fibers display higher absorption for the red dye with the exception of the concentration of $3 \%$. The absorption behavior of the blue dye is more dependent on its initial concentration showing the higher values for cotton. Banana fibers show greater adsorption for a concentration of $1 \%$ while curaua for higher concentrations. The results showed higher affinity for lignocellulosic substrate depending on the dye chemical structure. Red and yellow dyes have similar structure carrying a triazine complex when a copper formazan complex characterizes the blue dye. It is clear that these fibers have a great potential showings similar or better dyeing ability when compared to cotton. Alkali treatment allows obtaining deeper colors at lower dye concentration generating less dyeing effluents. The dye uptake into the fibers demonstrates a graphical feature of an isothermal. Confirming that, the dyeing of curaua and banana fibers is governed by the Langmuir isotherm (data not shown). Alkaline treatment causes a decrease in dye affinity for the lignocellulosic fibers. These results are interesting from the point of view of the dye entrance in the fiber interior, because the affinity is inversely proportional to the diffusion coefficient.

The results of washing fastness at $40^{\circ} \mathrm{C}$ are very good in confirming the level of dye diffusion and fixation into the fiber. Values of 4-5 for color staining were obtained for all the fibers of the multifiber fabric (AC, CO, PA, PES, PAC, and WO).
The durability of the membrane largely depends on its water absorption. The membrane used in this work exhibited water absorption and apparent porosity of 15.3 and $40.2 \%$, respectively. The value for apparent specific gravity of $2.6 \mathrm{~g} \mathrm{~cm}^{-3}$ is in accordance with the theoretical density of the formulation calculated from the ideal chemical composition. The used high sintering temperature has a positive effect on membrane flexural strength exhibiting a three-point flexural strength value of $37 \mathrm{Mpa}$ at room temperature [19]. The primary goal in sintering is to impart sufficient mechanical strength to the membranes while maintaining sufficient permeability. Sintering stress damages do not occur in $\alpha$-alumina at temperatures up to $1,250{ }^{\circ} \mathrm{C}$, however for higher temperature a careful control of this process is crucial, especially when the membranes containing different materials such as PVA and EG. The addition of PVA could reduce the thermal stability of the alumina membranes at high temperatures; however, it prevents the formation of cracking reducing the stress during the drying process and enhances the strength and viscosity of the network [27]. Another polymer with relatively high polarity, viscosity, and water miscibility such as EG was added to improve the wetting of alumina and to reduce the friction between particles during compression [28]. An initial set of tests was performed to evaluate the main properties of the membranes sintered under different condition of time and temperature $\left(1,350{ }^{\circ} \mathrm{C}\right.$ at $2 \mathrm{~h}, 1,450{ }^{\circ} \mathrm{C}$ at $30 \mathrm{~min}$ and $2 \mathrm{~h}, 1,475^{\circ} \mathrm{C}$ at $30 \mathrm{~min}$ and $2 \mathrm{~h}$ ). A clear growth in density was observed while increasing the sintering temperature up to $1,475^{\circ} \mathrm{C}$. At higher sintering temperatures, a decrease in density was observed (data not shown) because of the excessive increase in average grain size at sintering temperatures higher than $1,500^{\circ} \mathrm{C}$. When the sintering temperature reached $1,475^{\circ} \mathrm{C}$, a more 


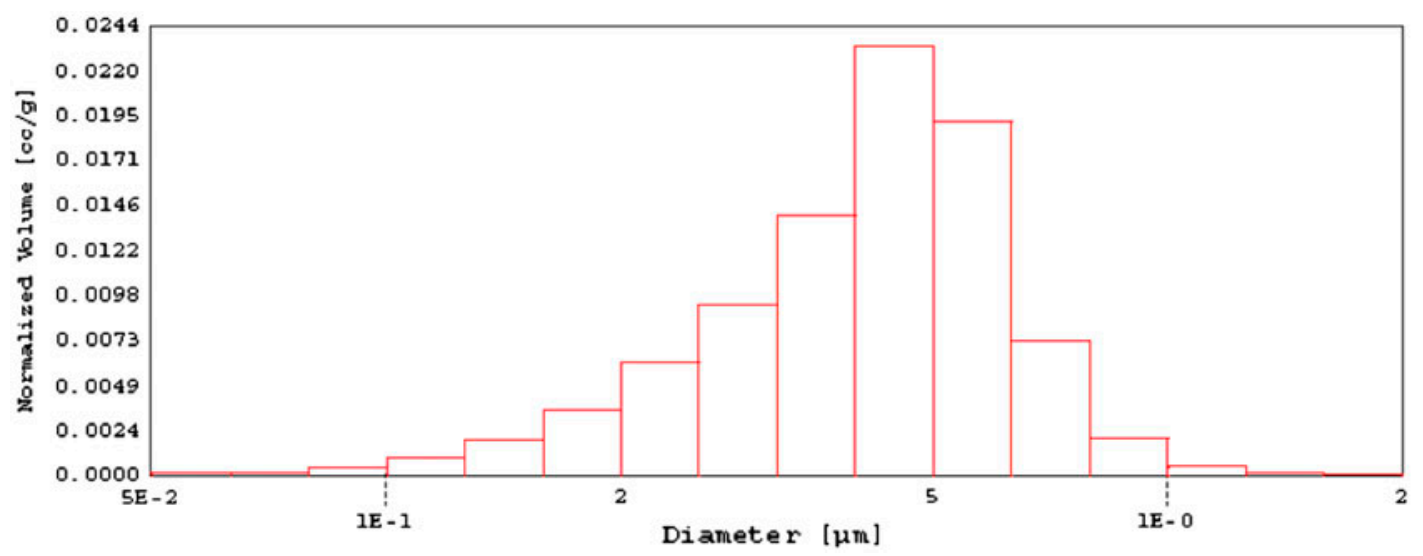

Fig. 4. Pore size distribution of the $\alpha$-alumina composite membrane sintered at $1,475^{\circ} \mathrm{C}$ for $2 \mathrm{~h}$.

dense-packed microstructure with the concomitant growth of the alumina grains can be observed. However, a sintering time of $30 \mathrm{~min}$ is not sufficient to reach an acceptable mechanical resistance. The best results in term of water adsorption, porosity, and mechanical resistance were obtained using a sintering time of $2 \mathrm{~h}$.

The durability of a membrane, beside its mechanical strength, also depends on water absorption behavior. Water absorption, which is the mass of moisture in the pores as a fraction of the mass of the sintered membrane, is an effective indicator of the quality of porous ceramic filters. The membrane sintered at $1,475^{\circ} \mathrm{C}$ exhibits a water absorption of $15.3 \%$ and a value of $2.6 \mathrm{~g} \mathrm{~cm}^{-3}$ in the apparent specific gravity that are in accordance with the theoretical density of the formulation calculated from the ideal chemical composition. As expected, the used temperatures have a positive effect on flexural strength resulting in superior strengths. The porous membrane exhibits a threepoint flexural strength value of $37 \mathrm{Mpa}$. The average pore size is $0.4 \mu \mathrm{m}$ with a pore monomodal distribution between 0.025 and $1.7 \mu \mathrm{m}$ (Fig. 4). The pore size is in accordance with the commercial microfiltration membranes for wastewater treatment ranging from 0.2 to $5 \mu \mathrm{m}$ (Table 2).

Fig. 5 illustrates SEM pictures of the membrane before and after filtration. Analysis of the membrane before filtration indicates the absence of pinholes cracks on the membrane structure making it suitable for microfiltration applications. The porosity of the membrane decreases after filtration but it was suitable for filtration in dead-end mode for 5 cycles. The results of the microfiltration experiments are presented in Table 3. All microfiltration experiments were conducted at room temperature under a pressure of 1 bar. The permeate flux of the used effluent was about
Table 2

Properties of the $\alpha$-alumina composite membrane sintered at $1,475^{\circ} \mathrm{C}$ for $2 \mathrm{~h}$. Data are means \pm standard deviations $(n=3)$

\begin{tabular}{ll}
\hline Burning linear retraction $(\%)$ & $5.4 \pm 0.6$ \\
Three-point flexural strength $(\mathrm{MPa})$ & $37.8 \pm 1.8$ \\
Mercury intrusion porosity interparticle $(\%)$ & $0.1 \pm 0.02$ \\
Mercury intrusion porosity intraparticle $(\%)$ & $25.4 \pm 0.4$ \\
Mercury intrusion porosity total $(\%)$ & $25.5 \pm 0.4$ \\
Pore distribution $(\mu \mathrm{m})$ & $0.025 \pm 1.7$ \\
Pore average $(\mu \mathrm{m})$ & $0.4 \pm 0.01$ \\
Water absorption $(\%)$ & $15.3 \pm 0.9$ \\
Apparent porosity $(\%)$ & $40.2 \pm 1.9$ \\
Apparent specific gravity $\left(\mathrm{g} \mathrm{cm}^{-3}\right)$ & $2.6 \pm 0.3$ \\
\hline
\end{tabular}

$150 \mathrm{~L} \mathrm{~h} \mathrm{~m}^{-2}$. This result is in agreement with permeate fluxes of alumina membranes in the literature [29]. Turbidity is a good indicator of the reduction of pollutants in the effluent by microfiltration. As it can be observed, the removal percentage of turbidity from effluents range from 95 to $97 \%$ removing almost the totality of colloidal particles or suspended solids. Considering the type of filtration, the color reduction is considerably elevated reaching $99 \%$ and allowing the reuse of the effluent for five filtration cycle. After the five cycles of filtration in dead-end mode, the membranes was cracked due to erosion. This result is quite surprising since so high color removal yields are usually obtained in ultra or nanofiltration [30]. Microfilters have been recently shown to be capable of removing soluble anionic dyes from aqueous solutions [31]. This high value could be explained by favorable molecular interactions of auxiliaries and mineral salt on dye removal efficiency [32]. It seems that the electrical effect could be in some cases more important than pore diameter when ionic dyes and salts are filtered. However, more studies will be necessary to 

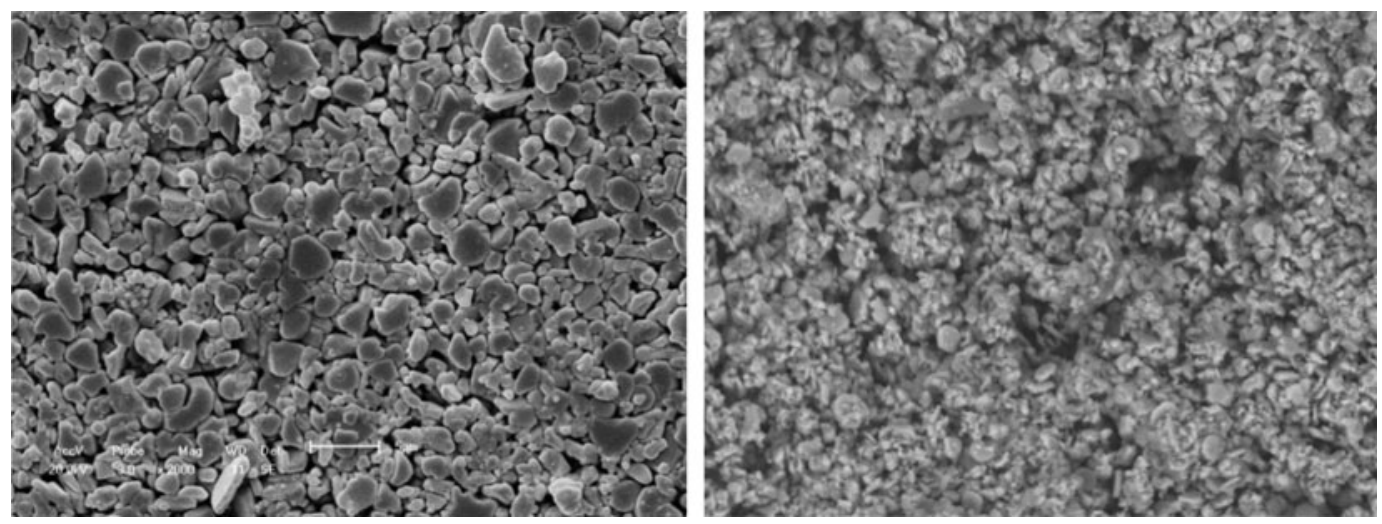

Fig. 5. SEM images $(2,000 \times)$ of the surface of $\alpha$-alumina composite membrane sintered at $1,475^{\circ} \mathrm{C}$ for $2 \mathrm{~h}$ before and after filtration.

Table 3

Percentages of color and turbidity reduction after microfiltration of the effluent of the three used dyes at the concentrations of 1 and 3\%. BF: before filtration; AF: after filtration; E: Removal efficiency. Data are means \pm standard deviations $(n=3)$

\begin{tabular}{|c|c|c|c|c|c|c|}
\hline \multirow[b]{2}{*}{ Dye (\% o.w.f) } & \multicolumn{3}{|c|}{ Color reduction $\left(\mathrm{mgPtCO} \mathrm{L}{ }^{-1}\right)$} & \multicolumn{3}{|c|}{ Turbidity reduction (NTU) } \\
\hline & $\mathrm{BF}$ & $\mathrm{AF}$ & $E(\%)$ & $\mathrm{BF}$ & $\mathrm{AF}$ & $E(\%)$ \\
\hline Y160 1 & $2,368.11 \pm 98.95$ & $31.54 \pm 0.93$ & 98.7 & $32.00 \pm 0.01$ & $0.84 \pm 0.01$ & 97.4 \\
\hline Y160 3 & $3,944.68 \pm 5.23$ & $42.15 \pm 1.24$ & 98.9 & $41.50 \pm 0.03$ & $1.05 \pm 0.01$ & 97.5 \\
\hline R198 1 & $2,304.48 \pm 10.03$ & $31.54 \pm 0.67$ & 98.6 & $13.60 \pm 0.14$ & $0.52 \pm 0.01$ & 96.2 \\
\hline R198 3 & $4,467.84 \pm 30.94$ & $45.68 \pm 1.56$ & 99.0 & $23.00 \pm 0.01$ & $0.69 \pm 0.03$ & 97.0 \\
\hline B220 1 & $1,593.59 \pm 7.92$ & $28.01 \pm 1.41$ & 98.2 & $17.92 \pm 0.01$ & $0.84 \pm 0.01$ & 95.3 \\
\hline B220 3 & $2,901.13 \pm 86.17$ & $38.61 \pm 0.83$ & 98.7 & $18.45 \pm 0.01$ & $0.89 \pm 0.01$ & 95.2 \\
\hline
\end{tabular}

understand the phenomena. In any case, the results show that microfiltration using alumina ceramic membranes is a realistic method for producing permeates of reusable quality.

\section{Conclusion}

SEM analysis of alkali-treated fibers show an increase in roughness due to defibrillation. Lignin and hemicellulose present in the fibers outer surface were dissolved exposing the inner fibrillar surface. DSC analysis showed for all the samples an endothermic peak between 50 and $100{ }^{\circ} \mathrm{C}$ due to the loss of adsorbed/absorbed water and a well-defined exothermic peak at $340-360^{\circ} \mathrm{C}$ attributed to decomposition of $\alpha$-cellulose. Alkali-treated fibers showed a second peak around $290^{\circ} \mathrm{C}$ attributed to the degradation of hemicellulose. The FTIR spectra of the studied fibers can be mainly attributed to the main components of cellulose-based materials. All samples contained similar bands, but differed in their intensities. Alkali-pretreated curaua and banana fibers showed an excellent dyeing ability for all the tested dyes. However, dye absorption in banana and curaua fibers depends to the chemical dye structure and concentration. Curaua fibers showed more intense color strength $(K / S)$ at high dye concentrations. The results of washing fastness are very good showing values of 4-5 for all the tested fibers. These results demonstrate that it is possible dye curaua and banana fibers using conventional reactive dyes with excellent color strength and washing fastness, creating opportunities for new added-value, greener and high-quality products. The developed membrane shows an average efficiency of $98 \%$ in turbidity and color reduction, demonstrating the feasibility of the use of porous alumina ceramic microfiltration membranes for textile effluent treatment and water reuse. The recycling and reuse of the treated effluent is a step forward for sustainable technologies based on membrane systems for large-scale ecologically friendly treatment processes. 


\section{Acknowledgment}

Andrea Zille (C2011-UMINHO-2C2T-01) acknowledges the funding from Programa Compromisso para a Ciência 2008, Portugal.

\section{References}

[1] T. Kudanga, E.N. Prasetyo, J. Sipilä, G.S. Nyanhongo, G.M. Guebitz, Enzymatic grafting of functional molecules to the lignin model dibenzodioxocin and lignocellulose material, Enzyme. Microb. Technol. 46 (2010) 272-280.

[2] C. Mancera, N.E. El Mansouri, M.A. Pelach, F. Francesc, J. Salvadó, Feasibility of incorporating treated lignins in fiberboards made from agricultural waste, Waste Manage. 32 (2012) 1962-1967.

[3] S.N. Monteiro, F.P.D. Lopes, A.P. Barbosa, A.B. Bevitori, I.L.A. Silva, L.L. Costa, Natural lignocellulosic fibers as engineering materials-An overview, Metall. Mater. Trans. A 42 (2011) 2963-2974.

[4] K.G. Satyanarayana, J.L. Guimarães, F. Wypych, Studies on lignocellulosic fibers of Brazil. Part I: Source, production, morphology, properties and applications. Composites Part A 38 (2007) 1694-1709.

[5] J. George, M.S. Sreekala, S. Thomas, A review on interface modification and characterization of natural fiber reinforced plastic composites, Polym. Eng. Sci. 41 (2001) 1471-1485.

[6] S. Mukhopadhyay, R. Fangueiro, Physical modification of natural fibers and thermoplastic films for composites-A review, J. Thermoplast. Compos. 22 (2009) 135-162.

[7] F.R. Oliveira, L. Erkens, R. Fangueiro, A.P. Souto, Surface modification of banana fibers by DBD plasma treatment. Plasma Chem. Plasma Process. 32 (2012) 259-273.

[8] A.C. Corrêa, E.D. de Morais Teixeira, L.A. Pessan, L.H.C. Mattoso, Cellulose nanofibers from curaua fibers, Cellulose 17 (2010) 1183-1192.

[9] R.V. Silva, E.M.F. Aquino, Curaua fiber: A new alternative to polymeric composites, J. Reinf. Plast. Compos. 27 (2008) 103-112.

[10] A. Gomes, T. Matsuo, K. Goda, J. Ohgi, Development and effect of alkali treatment on tensile properties of curaua fiber green composites, Composites Part A 38 (2007) 1811-1820.

[11] M.A.S. Spinacé, K.K.G. Fermoseli, M.A. De Paoli, Recycled polypropylene reinforced with curaua fibers by extrusion, J. Appl. Polym. Sci. 112 (2009) 3686-3694.

[12] M. Idicula, S.K. Malhotra, K. Joseph, S. Thomas, Effect of layering pattern on dynamic mechanical properties of randomly oriented short banana/sisal hybrid fiberreinforced polyester composites, J. Appl. Polym. Sci. 97 (2005) 2168-2174.

[13] S.M. Sapuan, A. Leenie, M. Harimi, Y.K. Beng, Mechanical properties of woven banana fibre reinforced epoxy composites, Mater. Des. 27 (2006) 689-693.

[14] K. Bilba, M.A. Arsene, A. Ouensanga, Study of banana and coconut fibers-Botanical composition, thermal degradation and textural observations, Bioresour. Technol. 98 (2007) 58-68.

[15] R.K. Misra, S. Kumar, K. Sandeep, A. Misra, Dynamic analysis of banana fiber reinforced high-density polyethylene/poly( $\varepsilon$-caprolactone) composites, J. Mech. Mater. Struct. 3 (2008) 107-125.

[16] H.H. Knudsen, H. Wenzel, Environmentally friendly method in reactive dyeing of cotton, Water Sci. Technol. 33 (1996) 17-27.

[17] DyStar, Levafix ${ }^{\circledR}$ and Remazol ${ }^{\circledR}$, High Performance Reactive Dyes for all Requirements and Processes, DyStar, Frankfurt, Germany, 1999.

[18] A.S.B. Narendra G, Accelerated bleaching of cotton material with hydrogen peroxide, J. Text. Sci. Eng. 3 (2013), doi: 10.4172/2165-8064.1000140.

[19] K.K.O.S. Silva, C.A. Paskocimas, F.R. Oliveira, J.H.O. Nascimento, A. Zille, Development of porous alumina membranes for treatment of textile effluent, Desalin. Water Treat. (2015) 1-9, doi: 10.1080/19443994.2015. 1018333.

[20] B. Deepa, E. Abraham, B.M. Cherian, A. Bismarck, J.J. Blaker, L.A. Pothan, A.L. Leao, S.F. de Souza, M. Kottaisamy, Structure, morphology and thermal characteristics of banana nano fibers obtained by steam explosion, Bioresour. Technol. 102 (2011) 1988-1997.

[21] M.J. John, R.D. Anandjiwala, Recent developments in chemical modification and characterization of natural fiber-reinforced composites, Polym. Compos. 29 (2008) 187-207.

[22] M.A.S. Spinacé, C.S. Lambert, K.K.G. Fermoselli, M.A. De Paoli, Characterization of lignocellulosic curaua fibres, Carbohydr. Polym. 77 (2009) 47-53.

[23] J.L. Guimarães, E. Frollini, C.G. da Silva, F. Wypych, K.G. Satyanarayana, Characterization of banana, sugarcane bagasse and sponge gourd fibers of Brazil, Ind. Crops Prod. 30 (2009) 407-415.

[24] M.M. Ibrahim, A. Dufresne, W.K. El-Zawawy, F.A. Agblevor, Banana fibers and microfibrils as lignocellulosic reinforcements in polymer composites, Carbohydr. Polym. 81 (2010) 811-819.

[25] F. Tomczak, K.G. Satyanarayana, T.H. Sydenstricker Studies on lignocellulosic fibers of Brazil: Part III-Morphology and properties of Brazilian curauá fibers, Composites Part A 38 (2007) 2227-2236.

[26] R. Kumar, V. Choudhary, S. Mishra, I.K. Varma, Banana fiber-reinforced biodegradable soy protein composites, Front. Chem. Chin. 3 (2008) 243-250.

[27] Y.S. Lin, A.J. Burggraaf, Preparation and characterization of high-temperature thermally stable alumina composite membrane, J. Am. Ceram. Soc. 74 (1991) 219-224.

[28] S. Ananthakumar, P. Manohar, K.G.K. Warrier, Effect of boehmite and organic binders on extrusion of alumina, Ceram. Int. 30 (2004) 837-842.

[29] A. Majouli, S. Tahiri, S. Alami Younssi, H. Loukili, A. Albizane, Elaboration of new tubular ceramic membrane from local Moroccan Perlite for microfiltration process. Application to treatment of industrial wastewaters, Ceram. Int. 38 (2012) 4295-4303.

[30] C. Fersi, L. Gzara, M. Dhahbi, Treatment of textile effluents by membrane technologies, Desalination 185 (2005) 399-409.

[31] J.J. Porter, P.J. Brown, J. Malphrus, Influence of $\mathrm{pH}$ on the rejection of salts and ionic dyes by microfilters, Desalination 184 (2005) 23-35.

[32] K.M. Majewska-Nowak, Application of ceramic membranes for the separation of dye particles, Desalination 254 (2010) 185-191. 